\title{
Pyramidal Neurons Are Not Generalizable Building Blocks of Cortical Networks
}

\author{
Jennifer I. Luebke* \\ Department of Anatomy and Neurobiology, Boston University School of Medicine, Boston, MA, USA
}

OPEN ACCESS

Edited by:

James A. Bourne,

Australian Regenerative Medicine

Institute, Australia

Reviewed by:

Mary Baldwin,

University of California, Davis, USA

Gavin John Clowry,

Newcastle University, UK

Marcello Rosa,

Monash University, Australia

*Correspondence:

Jennifer I. Luebke

jluebke@bu.edu

Received: 03 December 2016

Accepted: 15 February 2017

Published: 07 March 2017

Citation:

Luebke Jl (2017) Pyramidal Neurons Are Not Generalizable Building Blocks of Cortical Networks.

Front. Neuroanat. 11:11.

doi: 10.3389/fnana.2017.00011
A key challenge in cortical neuroscience is to gain a comprehensive understanding of how pyramidal neuron heterogeneity across different areas and species underlies the functional specialization of individual neurons, networks, and areas. Comparative studies have been important in this endeavor, providing data relevant to the question of which of the many inherent properties of individual pyramidal neurons are necessary and sufficient for species-specific network and areal function. In this mini review, the importance of pyramidal neuron structural properties for signaling are outlined, followed by a summary of our recent work comparing the structural features of mouse (C57/BL6 strain) and rhesus monkey layer 3 (L3) pyramidal neurons in primary visual and frontal association cortices and their implications for neuronal and areal function. Based on these and other published data, L3 pyramidal neurons plausibly might be considered broadly "generalizable" from one area to another in the mouse neocortex due to their many similarities, but major differences in the properties of these neurons in diverse areas in the rhesus monkey neocortex rules this out in the primate. Further, fundamental differences in the dendritic topology of mouse and rhesus monkey pyramidal neurons highlight the implausibility of straightforward scaling and/or extrapolation from mouse to primate neurons and cortical networks.

Keywords: mouse, rhesus monkey, comparative anatomy, dendrites, spines, synapses, visual cortex, prefrontal cortex

The mammalian neocortex is a complex cellular structure endowed with exquisite computational powers. Excitatory pyramidal neurons and inhibitory interneurons together form long range and local networks which invest different cortical areas with the capacity to perform highly distinctive tasks such as visual encoding and mediation of executive functions. An influential idea has been that prototypical, generalizable pyramidal neurons comprise the basic building blocks of canonical cortical circuits or minicolumns which, once fully understood, can be extrapolated from one brain area or species to another (e.g., Douglas and Martin, 2004, 2007a,b). The view that individual neuron properties are conserved in different species and cortical areas has arisen from the existence of certain regularities in their basic design, the connections they have and the circuits they comprise, and it has been suggested that generalizable themes may allow for compression of connectomics data (in DeFelipe, 2015; DeFelipe et al., 2016).

The advent of large-scale brain mapping initiatives such as the Human Brain Project and the BRAIN Initiative highlight the need for ascertaining which, if any, data on the fundamental features of neurons can be extrapolated from one cortical area to another and from the rodent to the primate brain. In the attempt to understand an entity as vastly complex as the mammalian neocortex, simplification and a reductionist approach is, for the time being, unavoidable. The goal is to identify 
the smallest number of variables that will still allow for biologically realistic neuronal, network, and areal behavior in brain models; in other words, to be "simple but not too simple" (DeFelipe, 2015; DeFelipe et al., 2016). The degree of detail about individual neuron structure and function required for modeling species-specific cortical network functions is controversial (e.g., Kupferschmidt, 2015), though this depends on the complexity of population behaviors being modeled (reviews: Sporns, 2014; Yuste, 2015).

Much of what is known about pyramidal neuron structure and function has been derived from laboratory rat and mouse primary sensory cortices, and these data form the basis of large scale brain mapping initiatives (e.g., Human Brain Project, Allen Cell Types Database) and constrain realistic models directed toward elucidating cortical network mechanisms (Egger et al., 2014; Markram et al., 2015). Gaining a thorough understanding of similarities and differences in neurons in different cortical areas (e.g., primary sensory vs. association) in the mouse, and between the mouse and primates, is thus a high priority. Specifically, the degree to which mouse and primate neurons are similar or differ has profound relevance for the generalizability of brain maps from the mouse to the primate and for the degree to which information from mouse models of human brain disorders can or cannot be translated to non-human primates and ultimately to human beings.

\section{STRUCTURE-FUNCTION RELATIONSHIPS IN PYRAMIDAL NEURONS- GENERAL THEMES}

Cortical pyramidal neuronal processes are present in each of the 6 neocortical layers, with somata typically localized to layers 2-6 (except in layer $4 c$ of the primary visual cortex, which is comprised exclusively of spiny stellate cells). The somata of pyramidal neurons are typically triangular, with a broad base from which a single axon and a skirt of basilar dendrites emanate and an apex from which, most typically, a single apical trunk projects. The apical dendrite has three compartments a main trunk, oblique branches, a tuft that ramifies in layer 1- each of which possesses unique structural, connectional, and functional characteristics which broaden the dynamic range of signal integration by the apical dendritic arbor as a whole. The different dendritic compartments receive and integrate distinct presynaptic excitatory and inhibitory inputs and possess distinct passive and active signal filtering and boosting capacities (Larkum et al., 2001, 2009; London and Hausser, 2005; Losonczy and Magee, 2006; Losonczy et al., 2008; reviews: Spruston, 2008; Kubota et al., 2015, 2016). Differences in the lengths, diameters, and branching pattern of the dendritic arbor confer significant variability in cable properties and therefore the spatial distribution of electrical signals and degree of summation of synaptic inputs, which determine the temporal pattern of both forward and backward propagating action potentials (Mainen

Abbreviations: sp, spine; asym, asymmetric (excitatory) synapse; PSD, postsynaptic density; Rn, input resistance; FR, firing rate; Aps, action potentials; sEPSC, spontaneous excitatory synaptic current; freq, frequency; amp- amplitude. and Sejnowski, 1996; Koch and Segev, 2000; Euler and Denk, 2001; Vetter et al., 2001; Krichmar et al., 2002; Ascoli, 2003; reviews: Stuart et al., 1997; Waters et al., 2005). Thus, by virtue of their different somatodendritic compartments, pyramidal neurons act as coincidence detectors possessing a wide dynamic range for integration of temporally and spatially unique synaptic signals. Computational modeling studies suggest that even minor differences in branching characteristics can exert a major influence on signal processing by neurons. For example, even modest variations in branch point angles can transform the electrical coupling between oblique dendrites and the main apical shaft dendrite from fully coupled to fully compartmentalized (Ferrante et al., 2013).

Integration of synaptic inputs is also significantly shaped by active properties, including the number and distribution of a wide variety of transmembrane ion channels (reviews: Migliore and Shepherd, 2002; Magee and Johnston, 2005; Johnston and Narayanan, 2008). Over 20 different types of sodium, calcium, and potassium channels are distributed -some uniformly and some non-uniformly- across a given dendrite and confer distinct boosting and/or dampening of local signals (reviews: Migliore and Shepherd, 2002; Magee and Johnston, 2005; Johnston and Narayanan, 2008; Nusser, 2012). The complex interplay of intrinsic ionic and synaptic conductances with passive properties determined by dendritic morphology can effectively alter the cable properties of the dendritic tree (Segev and London, 2000; Bekkers and Häusser, 2007; review: Nusser, 2012) resulting in a variable and finely-tunable integrative and signaling capacity in pyramidal neurons.

Dendritic spines -principal recipients of glutamatergic synapses- also play a key role in the electrical and biochemical signaling in dendrites (reviews: Matus and Shepherd, 2000; Nimchinsky et al., 2002; Kasai et al., 2003; Bourne and Harris, 2008). While there is a continuum of spine morphology at steady state, and morphology can vary dynamically in response to synaptic activity (Lendvai et al., 2000; Zuo et al., 2005; for review: Lüscher et al., 2000; Wefelmeyer et al., 2016), spines can be broadly classified as being "thin," "stubby," "mushroom," or "filopodia" (review: Bourne and Harris, 2008). Just as with dendrites, spine structural properties underlie functional physiological signaling; thus spine and synapse structure is largely determinative of the strength, stability and function of excitatory glutamatergic synapses (Tong and Jahr, 1994; Baude et al., 1995; Murthy et al., 1997, 2001; Nusser et al., 1998; Matsuzaki et al., 2001; Li et al., 2005; Germuska et al., 2006). Thus, quantification of the distribution of spine subtypes as well as of synapses on pyramidal neurons is essential for understanding the integrative capacities of these neurons in distinct brain areas and species.

\section{L3 PYRAMIDAL NEURON MORPHOLOGY VARIES DEPENDING ON BRAIN AREA AND SPECIES}

Dendritic arbor size and spine density on pyramidal neurons differ markedly across functionally distinct cortical areas in the 
rhesus monkey and the human brain (Cajal SRy, 1894, 1995; Conel, 1941, 1967; DeFelipe et al., 2002; Jacobs, 2002; Elston, 2003; Elston and Fujita, 2014; Mohan et al., 2015). In the rhesus monkey, the size, and complexity of the dendritic arbors of L3 pyramidal neurons increases dramatically from primary visual cortex (V1) to higher-order lateral prefrontal cortex, and this increase in overall size is accompanied by a significantly higher spine density (Elston, 2000, 2002, 2003; Elston et al., 2001; Amatrudo et al., 2012). In addition to this caudal to rostral gradient observed in the primate, pyramidal neurons in some analogous cortical areas increase in size or "scale" from the rodent to the macaque (Elston and DeFelipe, 2002; Elston and Zeitsch, 2005; Ballesteros-Yanez et al., 2006; Elston, 2007; Wen et al., 2009; Elston and Manger, 2014; reviews: Wittenberg and Wang, 2008; DeFelipe, 2011).

To gain a deeper understanding of comparative morphological features of cortical neurons in rodents and primates, as well as their functional relevance, we have used in vitro whole-cell patch-clamp recordings and cell filling in a series of systematic studies to characterize the detailed structural, neuro-chemical and functional properties of L3 pyramidal neurons in the primary visual and frontal association cortices of mice and of rhesus monkeys (Amatrudo et al., 2012; Luebke et al., 2015; Medalla and Luebke, 2015; Gilman et al., 2016; Hsu et al., in press). A unique feature of these studies, which are summarized below, is that neurons were assessed both morphologically and physiologically at high resolution and in an identical manner across different brain areas in the two species allowing direct and comprehensive comparisons.

\section{L3 PYRAMIDAL NEURONS IN PRIMARY VISUAL AND FRONTAL ASSOCIATION AREAS IN THE RHESUS MONKEY AND IN THE MOUSE}

\section{Rhesus Monkey}

L3 pyramidal neurons in V1 and LPFC of the rhesus monkey are highly distinctive across a broad spectrum of structural and functional properties (Elston, 2000, 2002; Elston et al., 2001; Amatrudo et al., 2012; Zaitsev et al., 2012; Medalla and Luebke, 2015; Gilman et al., 2016; Hsu et al., in press). Most prominently, the dendritic arbors of LPFC neurons are on average $2.5 \mathrm{x}$ larger than those of $\mathrm{V} 1$ neurons and are also significantly more complex, with twice as many branch points (Figure 1; Table 1). The smaller size of V1 neurons is related to a higher input resistance, lower rheobase and higher evoked action potential firing rates compared to LPFC neurons (Amatrudo et al., 2012; Table 1). Further, the mean number and mean density of dendritic spines are $\sim 5$-fold and $\sim 2$-fold higher, respectively, on monkey LPFC than on V1 neurons (Elston and Rosa, 1997; Elston, 2003; Amatrudo et al., 2012; Medalla and Luebke, 2015; Table 1). Interestingly however the numeric density of asymmetric excitatory synapses in the layer $2 / 3$ neuropil of these two areas does not differ (Hsu et al., in press). These apparently incongruous findings can be explained by the fact that the density of neurons in V1 (and hence the density of synapses) is significantly higher than in LPFC in the monkey. Electron microscopic assessment of excitatory synapse ultrastructure in layer $2 / 3$ neuropil reveal that presynaptic boutons and postsynaptic densities of axospinous synapses are significantly larger in monkey LPFC compared to those in V1. It is of key functional significance that there is also a higher proportion of large perforated synapses in LPFC neuropil (Figure 1; Table 1) since this feature of postsynaptic densities is associated with long-term potentiation of glutamatergic synaptic responses (review: Lüscher et al., 2000; Wefelmeyer et al., 2016). The existence of larger synapses in LPFC, together with the much higher density of spines, likely provide the structural underpinning of the significantly larger and more frequent synaptic currents -that is, enhanced synaptic efficacy- seen in LPFC compared to V1 with whole-cell patch-clamp recordings (Amatrudo et al., 2012; Medalla and Luebke, 2015; Table 1).

\section{Mouse}

Whether, there is a homolog for the primate LPFC in the mouse or rat has been a matter of some discussion and debate (Preuss, 1995; Uylings et al., 2003; Kolb, 2007; Wise, 2008; Van De Werd et al., 2010; Barbas, 2015). The mouse cortical area that is arguably the closest anatomical analog is the dorsomedial frontal cortex (including area FR2) which receives dense inputs from the mediodorsal nucleus of the thalamus (Guldin et al., 1981; Van De Werd et al., 2010) just as the LPFC of the primate does. In marked contrast to the significant differences in L3 pyramidal neurons observed between these two areas in the rhesus monkey, L3 pyramidal neurons in the mouse V1 and FC (FR2) exhibit very modest differences in dendritic structural properties -V1 neurons being slightly smaller than FC- and are nearly identical with regard to physiological features assessed in vitro (Table 1). In the mouse there is also no areal difference in the number or density of dendritic spines on V1 and FC L3 pyramidal neurons or in the ultrastructural properties of excitatory synapses in the two areas. Predictably, excitatory synaptic currents are similarly indistinguishable between mouse FC and V1 neurons by marked contrast to the major differences in these currents between monkey LPFC and V1 (Table 1).

\section{STRUCTURE OF NEURONS IN PRIMARY VISUAL AND FRONTAL ASSOCIATION AREAS IN THE MOUSE COMPARED TO THE RHESUS MONKEY}

While frontal cortical L3 pyramidal neurons scale significantly in size from the mouse to the monkey, no such scaling exists with L3 pyramidal neurons in V1 (Gilman et al., 2016). That dendritic scaling occurs in frontal but not visual L3 pyramidal neurons provides interesting insight into potentially differential capabilities of these neurons in the two species. As frontal cortical pyramidal neurons increase in size across phylogeny, the opportunity for convergence of diverse inputs is increased, as is their integrative and computational dynamic range. As discussed above, integration and filtering of input signals occurs as a function of number of dendritic branch points and both diameter 


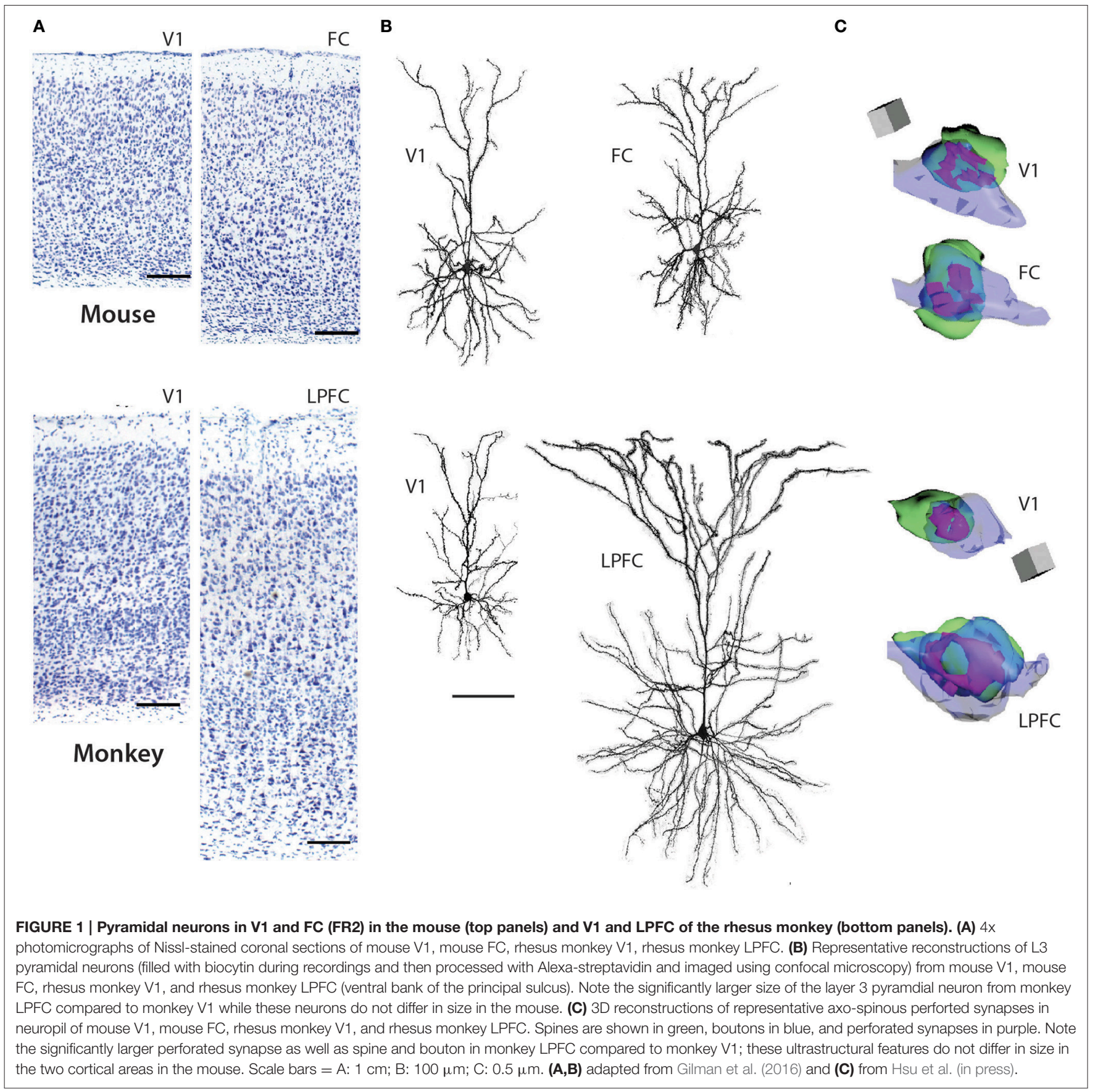

and the geometric features -notably length and diameter- of dendritic segments (Rall, 1962, 1964). Scaling and cable theory predict that monkey LPFC neurons filter input signals to a greater extent than mouse FC neurons due to their greater dendritic length and equivalent dendritic diameters. Consistent with this, there is a higher frequency of spontaneous EPSCs in mouse FC vs. monkey LPFC (Gilman et al., 2016). On the other hand, action potential firing and other intrinsic properties are largely preserved between mouse and monkey frontal neurons, suggesting significant roles for non-passive properties (e.g., active conductances and synaptic inputs; Nusser, 2012) that should be examined in future studies. V1 neurons in the monkey possess the lowest number and density of spines while spine densities do not significantly differ between monkey LPFC and mouse FC and mouse V1 neurons, though given their much smaller size, the mean numbers of spines on pyramidal neurons in the mouse is much lower than in monkey LPFC (Gilman et al., 2016). The ultrastructural properties of excitatory synapses vary across species in that the L2-3 neuropil of monkey LPFC contains a significantly higher proportion of perforated postsynaptic 
TABLE 1 | Comparative structural and functional features of neurons and excitatory synapses in C57/BL6 mouse and rhesus monkey (Macaca mulatta) V1 and FC/LPFC.

\begin{tabular}{|c|c|c|c|c|c|c|c|c|c|c|c|c|}
\hline & \multicolumn{2}{|c|}{ MouseV1 } & \multicolumn{2}{|c|}{ MouseFC } & \multicolumn{2}{|c|}{ MonkeyV1 } & \multicolumn{2}{|c|}{ MonkeyLPFC } & \multirow{2}{*}{$\begin{array}{l}\text { Mouse } \\
\text { VI vs. } \\
\text { FC }\end{array}$} & \multirow{2}{*}{$\begin{array}{l}\text { Monkey } \\
\text { VI vs. } \\
\text { LPFC }\end{array}$} & \multirow{2}{*}{$\begin{array}{c}\text { Mouse vs. Monkey } \\
\text { VI }\end{array}$} & \multirow{2}{*}{$\begin{array}{c}\text { Mouse vs. Monkey } \\
\text { FC and LPFC }\end{array}$} \\
\hline & Mean & SEM & Mean & SEM & Mean & SEM & Mean & SEM & & & & \\
\hline Soma Diameter $(\mu \mathrm{m})$ & 14.9 & 0.4 & 15.8 & 0.5 & 12.7 & 0.5 & 17.3 & 0.9 & ns & $p<0.001$ & $p<0.001$ & ns \\
\hline Dendritic Length ( $\mu \mathrm{m})$ & 4,291 & 261 & 5,034 & 241 & 3,188 & 226 & 7,631 & 919 & ns & $p<0.01$ & ns & $p<0.01$ \\
\hline \# Branch Points & 44 & 3.5 & 49.3 & 2.9 & 32 & 2.6 & 51.3 & 5.6 & ns & $p<0.01$ & ns & ns \\
\hline Spine Number & 4,377 & 302 & 4,819 & 534 & 1,884 & 216 & 10,018 & 2,062 & ns & $p<0.001$ & $p<0.01$ & $p<0.01$ \\
\hline Spine Density (sp/ $\mu \mathrm{m})$ & 0.99 & 0.08 & 0.95 & 0.07 & 0.6 & 0.03 & 1.12 & 0.18 & ns & $p<0.001$ & $p<0.05$ & ns \\
\hline \multicolumn{13}{|c|}{ Synapse Density $\left(\mathrm{N}_{\mathrm{V}} \times 10^{6} / \mathrm{mm}^{3}\right)$} \\
\hline All Asym & 0.93 & 0.08 & 1.05 & 0.13 & 0.48 & 0.06 & 0.45 & 0.04 & ns & ns & $p<0.0001$ & $p<0.0001$ \\
\hline Asym AxoSp & 0.86 & 0.09 & 0.99 & 0.11 & 0.37 & 0.05 & 0.37 & 0.04 & ns & $\mathrm{ns}$ & $p<0.0001$ & $p<0.0001$ \\
\hline Asym AxoDen & 0.07 & 0.02 & 0.06 & 0.02 & 0.12 & 0.01 & 0.08 & 0.00 & ns & $p<0.043$ & $p<0.018$ & ns \\
\hline$\%$ perforated synapses & 23.3 & 0.4 & 19.5 & 4.0 & 20.2 & 4.7 & 34.8 & 1.5 & ns & $p<0.003$ & ns & $p<0.004$ \\
\hline \multicolumn{13}{|l|}{ PSD area $\left(\mu \mathrm{m}^{3}\right)$} \\
\hline All & 0.084 & 0.008 & 0.075 & 0.020 & 0.082 & 0.010 & 0.116 & 0.009 & ns & $p<0.028$ & ns & $p<0.017$ \\
\hline Non-perforated & 0.061 & 0.006 & 0.050 & 0.011 & 0.075 & 0.011 & 0.071 & 0.006 & ns & ns & ns & ns \\
\hline Perforated & 0.152 & 0.021 & 0.160 & 0.030 & 0.113 & 0.013 & 0.199 & 0.018 & ns & $p<0.003$ & ns & ns \\
\hline \multicolumn{13}{|l|}{ Spine volume $\left(\mu \mathrm{m}^{3}\right)$} \\
\hline All & 0.069 & 0.020 & 0.048 & 0.016 & 0.066 & 0.009 & 0.102 & 0.006 & ns & $p<0.021$ & ns & $p<0.004$ \\
\hline Non-perforated & 0.050 & 0.012 & 0.034 & 0.010 & 0.061 & 0.008 & 0.061 & 0.005 & ns & ns & ns & $p<0.025$ \\
\hline Perforated & 0.128 & 0.033 & 0.107 & 0.023 & 0.086 & 0.011 & 0.181 & 0.008 & ns & $p<0.001$ & ns & $p<0.007$ \\
\hline \multicolumn{13}{|l|}{ Electrophysiology } \\
\hline $\mathrm{Rn}(\mathrm{MOhm})$ & 229 & 12 & 215 & 17 & 224 & 21 & 102 & 9 & ns & $p<0.001$ & ns & $p<0.001$ \\
\hline Rheobase (pA) & 96.7 & 7.6 & 81.9 & 7 & 80.2 & 8.3 & 144.7 & 15.8 & ns & $p<0.05$ & ns & $p<0.05$ \\
\hline 80 pA FR (APs/sec) & 5.6 & 0.7 & 5.4 & 1.3 & 14.9 & 1.8 & 5.4 & 1.8 & ns & $p<0.001$ & $p<0.001$ & ns \\
\hline sEPSC Freq $(\mathrm{Hz})$ & 4.6 & 0.4 & 3.3 & 0.2 & 1.2 & 0.2 & 2.9 & 0.5 & ns & $p<0.05$ & $p<0.01$ & $p<0.01$ \\
\hline sEPSC Amp (pA) & 13.5 & 1.5 & 9.8 & 0.5 & 7.3 & 0.4 & 14 & 2.1 & ns & $p<0.01$ & ns & ns \\
\hline sEPSC Rise (ms) & 1.75 & 0.11 & 1.61 & 0.07 & 1.22 & 0.1 & 1.85 & 0.21 & ns & $p<0.01$ & ns & ns \\
\hline sEPSC Decay (ms) & 7.7 & 0.34 & 6.62 & 0.18 & 4.63 & 0.5 & 7.77 & 0.69 & ns & $p<0.01$ & ns & ns \\
\hline
\end{tabular}

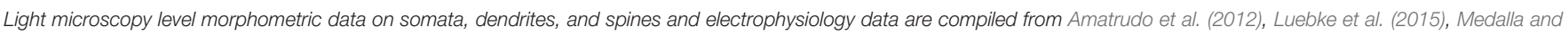

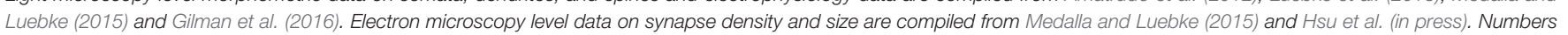
of subjects and cells analyzed for each variable are provided in these original citations.

densities and, on average, larger spine volume compared to L2-3 neuropil of mouse FC. Finally, both presynaptic and postsynaptic entities are significantly smaller in the mouse FC than in the monkey LPFC.

\section{IMPLICATIONS FOR SPECIES-SPECIFIC CORTICAL AREAL SPECIALIZATION}

L3 pyramidal neurons in mouse FC and V1 are virtually identical in their dendritic, spine, and excitatory synapse structure as well as in their physiological properties. These findings are in line with the high degree of cytoarchitectural and functional homogeneity across mouse cortical areas, compared to the highly specialized cortical areas of the primate brain. The similarity in the structural and biophysical properties of mouse V1 and FC neurons suggests that relatively similar temporal signaling dynamics may exist within these areas. In mice, both the primary sensory area V1 and the multimodal FC contain cellular and synaptic features consistent with a highly excitable circuit, being comprised of small and electrically compact output neurons, and abundant spines with relatively small excitatory synapses. Thus, in broad terms mouse cortical neurons (and presumably the dynamic networks of which they are a part) are well suited for rapid synaptic transmission with a high degree of input-output fidelity but relatively low dynamic range (review: Olshausen and Field, 2004; Vogels et al., 2005; Panzeri et al., 2010).

In contrast to the small and much less differentiated rodent neocortex, a larger and more specialized brain, such as that of the rhesus monkey, requires functionally distinct cortical areas to have different levels of excitability, filtering, and integration of inputs (Luebke et al., 2010; Barbas, 2015). The preponderance of morphological and electrophysiological data predict that in the monkey, synaptic integration at the cellular and network levels differ between V1, a primary sensory area for unimodal representation, and LPFC, a high-order area for complex multimodal processing (review: Schummers et al., 2004; Fuster, 2015). V1 neurons are small, compact and highly 
excitable, properties that enable them to respond optimally to small, fast synaptic inputs and for building a network with a limited dynamic range but well-suited for signal transformations with relatively high input-output fidelity (review: Olshausen and Field, 2004; Vogels et al., 2005; Panzeri et al., 2010). Compared to the primary sensory V1, the multimodal association LPFC in monkey is comprised of cellular and synaptic featureslarge and electrotonically complex L3 output neurons with many spines- consistent with more powerful and longer-lasting inputs. These features are optimal for facilitating sustained activation, coincidence detection, and spike-timing-dependent plasticity, all important for integrative functions such as decision making and integration of sensorimotor information (review: Constantinidis and Wang, 2004; Sjostrom et al., 2008). The function of the LPFC is to integrate multimodal information from a wide array of cortical and subcortical afferents in order to perform sophisticated executive tasks (review: Miller and Cohen, 2001; Luebke et al., 2010). A relatively larger dynamic range of integration of information conferred by larger neurons with more numerous synapses is required in a high-order area such as LPFC, while it would be disadvantageous in V1 where more rapid signal transformations are required.

\section{CONCLUSIONS}

In terms of their fundamental structural properties -dendrite, spine, and synapse morphology- there are some striking and many subtle differences between L3 pyramidal neurons in the mouse and the rhesus monkey and between cortical areas in the rhesus monkey but not in the mouse. In the mouse, where L3 pyramidal neurons are structurally the same in these two brain areas, a uniform prototypical cortical pyramidal neuron may be generalizable from one area to another, at least in terms of size, dendritic structure, and intrinsic membrane, synaptic, and action potential firing properties. In the rhesus monkey such a prototypical neuron does not exist- cortical areas differ markedly from each other at the individual pyramidal cell and network levels. Data such as those summarized here are

\section{REFERENCES}

Amatrudo, J. M., Weaver, C. M., Crimins, J. L., Hof, P. R., Rosene, D. L., and Luebke, J. I. (2012). Influence of highly distinctive structural properties on the excitability of pyramidal neurons in monkey visual and prefrontal cortices. J. Neurosci. 32, 13644-13660. doi: 10.1523/JNEUROSCI.2581-1 2.2012

Ascoli, G. A. (2003). Passive dendritic integration heavily affects spiking dynamics of recurrent networks. Neural Netw. 16, 657-663. doi: 10.1016/S0893-6080(03)00090-X

Ballesteros-Yanez, I., Benavides-Piccione, R., Elston, G. N., Yuste, R., and DeFelipe, J. (2006). Density and morphology of dendritic spines in mouse neocortex. Neuroscience 138, 403-409. doi: 10.1016/j.neuroscience.2005. 11.038

Barbas, H. (2015). General cortical and special prefrontal connections: principles from structure to function. Annu. Rev. Neurosci. 38, 269-289. doi: 10.1146/annurev-neuro-071714-033936

Baude, A., Nusser, Z., Molnar, E., Mcllhinney, R. A., and Somogyi, P. (1995). High-resolution immunogold localization of AMPA type glutamate receptor important for understanding how signaling within neuronal networks differs between rodents and primates and for how these neurons and networks may contribute to species-specific functional capacities. These findings however do not answer the question of which, if any, of these particular differences are necessary and sufficient for differentiating neuronal network behavior in different brain areas and species. The answer to this question remains to be determined and is difficult to predict, particularly in light of in silico predictions that neuronal networks display emergent behavior that may not depend on details of individual neuron structure and function (review: Yuste, 2015). For now, since we do not know which of myriad details about individual neurons are key for network function, the tendency for premature simplification should be avoided (DeFelipe et al., 2016). Our understanding of neuronal diversity in all of its complexity is nascent, but thanks to advances in molecular, genetic and neuroanatomical tools we are on the verge of a new era in which the great diversity of neuronal types will be cataloged and lead to more nuanced and comprehensive insights into the mechanisms of cortical areal specialization.

\section{AUTHOR CONTRIBUTIONS}

The author confirms being the sole contributor of this work and approved it for publication.

\section{ACKNOWLEDGMENTS}

The author is grateful to the following individuals for their work on neuronal diversity and for many useful conversations: Drs. Anne Rocher, Johanna Crimins, Joseph Amatrudo, Kathy Rockland, Alan Peters, Christina Weaver and Maria Medalla as well as to Joshua Gilman, Alex Hsu and Teresa GuillamonVivancos. Work from the Luebke lab described in this mini review is supported by grants from the National Institutes of Health, USA including NIH/NIA P01-AG00001, R01 AG025062, R01 AG035071. subunits at synaptic and non-synaptic sites in rat hippocampus. Neuroscience 69, 1031-1055. doi: 10.1016/0306-4522(95)00350-R

Bekkers, J. M., and Häusser, M. (2007). Targeted dendrotomy reveals active and passive contributions of the dendritic tree to synaptic integration and neuronal output. Proc. Natl. Acad. Sci. U.S.A. 104, 11447-11452. doi: 10.1073/pnas.0701586104

Bourne, J. N. and Harris, K. M. (2008). Balancing structure and function at hippocampal dendritic spines. Annu. Rev. Neurosci. 31, 47-67. doi: 10.1146/annurev.neuro.31.060407.125646

Cajal SRy (1894). Estructura intima de los centros nerviosos. Rev. Ciencias Med. 20, 145-160.

Cajal SRy (1995). Histology of the Nervous System of Man and Vertebrates. New York, NY: Oxford Universiy Press.

Conel, J. L. (1941). The Cortex of a One Month Old Infant. Cambridge, MA: Harvard University Press.

Conel, J. L. (1967). The Cortex of a Six Year Old Child. Cambridge, MA: Harvard University Press.

Constantinidis, C., and Wang, X. J. (2004). A neural circuit basis for spatial working memory. Neuroscientist 10, 553-565. doi: 10.1177/1073858404268742 
DeFelipe, J. (2011). The evolution of the brain, the human nature of cortical circuits, and intellectual creativity. Front. Neuroanat. 5:29. doi: 10.3389/fnana.2011.00029

DeFelipe, J. (2015). The anatomical problem posed by brain complexity and size: a potential solution. Front. Neuroanat. 9:104. doi: 10.3389/fnana.2015.00104

DeFelipe, J., Alonso-Nanclares, L., and Arellano, J. I. (2002). Microstructure of the neocortex: comparative aspects. J. Neurocytol. 31, 299-316. doi: 10.1023/A:1024130211265

DeFelipe, J., Douglas, R. J., Hill, S. L., Lein, E. S., Martin, K. A., Rockland, K. S., et al. (2016). Comments and general discussion on "The anatomical problem posed by brain complexity and size: a potential solution." Front. Neuroanat. 10:60. doi: $10.3389 /$ fnana.2016.00060

Douglas, R. J., and Martin, K. A. (2004). Neuronal circuits of the neocortex. Annu. Rev. Neurosci. 27, 419-451. doi: 10.1146/annurev.neuro.27.070203.144152

Douglas, R. J., and Martin, K. A. (2007a). Recurrent neuronal circuits in the neocortex. Curr. Biol. 17, R496-R500. doi: 10.1016/j.cub.2007.04.024

Douglas, R. J., and Martin, K. A. (2007b). Mapping the matrix: the ways of neocortex. Neuron 56, 226-238. doi: 10.1016/j.neuron.2007.10.017

Egger, R., Dercksen, V. J., Udvary, D., Hege, H. C., and Oberlaender, M. (2014). Generation of dense statistical connectomes from sparse morphological data. Front. Neuroanat. 8:129. doi: 10.3389/fnana.2014.00129

Elston, G. N. (2000). Pyramidal cells of the frontal lobe: all the more spinous to think with. J. Neurosci. 20:RC95.

Elston, G. N. (2002). Cortical heterogeneity: implications for visual processing and polysensory integration. J. Neurocytol. 31, 317-335. doi: 10.1023/A:1024182228103

Elston, G. N. (2003). Cortex, cognition and the cell: new insights into the pyramidal neuron and prefrontal function. Cereb. Cortex 13, 1124-1138. doi: 10.1093/cercor/bhg093

Elston, G. N. (2007). "Evolution of the pyramidal cell in primates," in Evolution of Nervous Systems, Vol. 4, eds J. Kaas and T. Preuss (New York, NY: Academic Press), 212-231.

Elston, G. N., Benavides-Piccione, R., and DeFelipe, J. (2001). The pyramidal cell in cognition: a comparative study in human and monkey. J. Neurosci 21:RC163.

Elston, G. N., and DeFelipe, J. (2002). Spine distribution in cortical pyramidal cells: a common organizational principle across species. Prog. Brain Res. 136, 109-133. doi: 10.1016/S0079-6123(02)36012-6

Elston, G. N., and Fujita, I. (2014). Pyramidal cell development: postnatal spinogenesis, dendritic growth, axon growth, and electrophysiology. Front. Neuroanat. 8:78. doi: 10.3389/fnana.2014.00078

Elston, G. N., and Manger, P. (2014). Pyramidal cells in V1 of African rodents are bigger, more branched and more spiny than those in primates. Front. Neuroanat. 8:4. doi: 10.3389/fnana.2014.00004

Elston, G. N., and Rosa, M. G. (1997). The occipitoparietal pathway of the macaque monkey: comparison of pyramidal cell morphology in layer III of functionally related cortical visual areas. Cereb. Cortex 7, 432-452. doi: $10.1093 /$ cercor/7.5.432

Elston, G. N., and Zeitsch, B. (2005). Fractal analyses as a tool for studying specialization in neuronal structure: the study of the evolution of the primate cerebral cortex and human intellect. Adv. Complex Syst. 8, 217-227. doi: $10.1142 /$ S0219525905000476

Euler, T., and Denk, W. (2001). Dendritic processing. Curr. Opin. Neurobiol. 11, 415-422. doi: 10.1016/S0959-4388(00)00228-2

Ferrante, M., Migliore, M., and Ascoli, G. A. (2013). Functional impact of dendritic branch-point morphology. J. Neurosci. 33, 2156-2165. doi: 10.1523/JNEUROSCI.3495-12.2013

Fuster, J. M. (2015). The Prefrontal Cortex: Anatomy, Physiology and Neuropsychology of the Frontal Lobe, 5th Edn. Philadelphia, PA: Lippincott-Raven.

Germuska, M., Saha, S., Fiala, J., and Barbas, H. (2006). Synaptic distinction of laminar-specific prefrontal-temporal pathways in primates. Cereb. Cortex 16, 865-875. doi: 10.1093/cercor/bhj030

Gilman, J. P., Medalla, M., and Luebke, J. I. (2016). Area-specific features of pyramidal neurons-a comparative study in mouse and rhesus monkey. Cereb. Cortex. doi: 10.1093/cercor/bhw062. [Epub ahead of print].

Guldin, W. O., Pritzel, M., and Markowitsch, H. J. (1981). Prefrontal cortex of the mouse defined as cortical projection area of the thalamic mediodorsal nucleus. Brain Behav. Evol. 19, 93-107. doi: 10.1159/000121636
Hsu, A., Luebke, J. I., and Medalla, M. (in press). Comparative ultrastructural features of excitatory synapses in the visual and frontal cortices of the adult mouse and monkey. J. Comp. Neurol.

Jacobs, B. S. A. B. (2002). "Regional dendritic variation in primate cortical pyramidal cells," in Cortical Areas: Unity and Diversity, ed A. M. R. Schüz (London: Taylor and Francis, Inc), 111-131.

Johnston, D., and Narayanan, R. (2008). Active dendrites: colorful wings of the mysterious butterflies. Trends Neurosci. 31, 309-316. doi: 10.1016/j.tins.2008.03.004

Kasai, H., Matsuzaki, M., Noguchi, J., Yasumatsu, N., and Nakahara, H. (2003). Structure-stability-function relationships of dendritic spines. Trends Neurosci. 26, 360-368. doi: 10.1016/S0166-2236(03)00162-0

Koch, C., and Segev, I. (2000). The role of single neurons in information processing. Nat. Neurosci. 3, 1171-1177. doi: 10.1038/81444

Kolb, B. (2007). "Do all mammals have a prefrontal cortex?," in The Evolution of Primate Nervous Systems, eds J. H. Kaas and L. Krubitzer (Amsterdam: Elsevier), 443-450.

Krichmar, J. L., Nasuto, S. J., Scorcioni, R., Washington, S. D., and Ascoli, G. A. (2002). Effects of dendritic morphology on CA3 pyramidal cell electrophysiology: a simulation study. Brain Res. 941, 11-28. doi: 10.1016/S0006-8993(02)02488-5

Kubota, Y., Karube, F., Nomura, M., and Kawaguchi, Y. (2016). The diversity of cortical inhibitory synapses. Front. Neural Circuits 10:27. doi: 10.3389/fncir.2016.00027

Kubota, Y., Kondo, S., Nomura, M., Hatada, S., Yamaguchi, N., Mohamed, A. A., et al. (2015). Functional effects of distinct innervation styles of pyramidal cells by fast spiking cortical interneurons. Elife 4:e07919. doi: 10.7554/eLife.07919

Kupferschmidt, K. (2015). Neuroscience. Virtual rat brain fails to impress its critics. Science 350, 263-264. doi: 10.1126/science.350.6258.263

Larkum, M. E., Nevian, T., Sandler, M., Polsky, A., and Schiller, J. (2009). Synaptic integration in tuft dendrites of layer 5 pyramidal neurons: a new unifying principle. Science 325, 756-760. doi: 10.1126/science.1171958

Larkum, M. E., Zhu, J. J., and Sakmann, B. (2001). Dendritic mechanisms underlying the coupling of the dendritic with the axonal action potential initiation zone of adult rat layer 5 pyramidal neurons. J. Physiol. 533, 447-466. doi: 10.1111/j.1469-7793.2001.0447a.x

Lendvai, B., Stern, E. A., Chen, B., and Svoboda, K. (2000). Experience-dependent plasticity of dendritic spines in the developing rat barrel cortex in vivo. Nature 404, 876-881. doi: 10.1038/35009107

Li, Z., Burrone, J., Tyler, W. J., Hartman, K. N., Albeanu, D. F., and Murthy, V. N. (2005). Synaptic vesicle recycling studied in transgenic mice expressing synaptopHluorin. Proc. Natl. Acad. Sci. U.S.A. 102, 6131-6136. doi: 10.1073/pnas.0501145102

London, M., and Hausser, M. (2005). Dendritic computation. Annu. Rev. Neurosci. 28, 503-532. doi: 10.1146/annurev.neuro.28.061604.135703

Losonczy, A., and Magee, J. C. (2006). Integrative properties of radial oblique dendrites in hippocampal CA1 pyramidal neurons. Neuron 50, 291-307. doi: 10.1016/j.neuron.2006.03.016

Losonczy, A., Makara, J. K., and Magee, J. C. (2008). Compartmentalized dendritic plasticity and input feature storage in neurons. Nature 452, 436-441. doi: 10.1038/nature06725

Luebke, J., Barbas, H., and Peters, A. (2010). Effects of normal aging on prefrontal area 46 in the rhesus monkey. Brain Res. Rev. 62, 212-232. doi: 10.1016/j.brainresrev.2009.12.002

Luebke, J. I., Medalla, M., Amatrudo, J. M., Weaver, C. M., Crimins, J. L., Hunt, B., et al. (2015). Age-related changes to layer 3 pyramidal cells in the rhesus monkey visual cortex. Cereb. Cortex 25, 1454-1468. doi: 10.1093/cercor/ bht 336

Lüscher, C., Nicoll, R. A., Malenka, R. C., and Muller, D. (2000). Synaptic plasticity and dynamic modulation of the postsynaptic membrane. Nat. Neurosci. 3, 545-550. doi: 10.1038/75714

Magee, J. C., and Johnston, D. (2005). Plasticity of dendritic function. Curr. Opin. Neurobiol. 15, 334-342. doi: 10.1016/j.conb.2005.05.013

Mainen, Z. F., and Sejnowski, T. J. (1996). Influence of dendritic structure on firing pattern in model neocortical neurons. Nature 382, 363-366. doi: $10.1038 / 382363 \mathrm{a} 0$

Markram, H., Muller, E., Ramaswamy, S., Reimann, M. W., Abdellah, M., Sanchez, C. A., et al. (2015). Reconstruction and simulation of 
neocortical microcircuitry. Cell 163, 456-492. doi: 10.1016/j.cell.2015. 09.029

Matsuzaki, M., Ellis-Davies, G. C., Nemoto, T., Miyashita, Y., Iino, M., and Kasai, H. (2001). Dendritic spine geometry is critical for AMPA receptor expression in hippocampal CA1 pyramidal neurons. Nat. Neurosci. 4, 1086-1092. doi: $10.1038 / \mathrm{nn} 736$

Matus, A., and Shepherd, G. M. (2000). The millennium of the dendrite? Neuron 27, 431-434. doi: 10.1016/S0896-6273(00)00054-4

Medalla, M., and Luebke, J. I. (2015). Diversity of glutamatergic synaptic strength in lateral prefrontal versus primary visual cortices in the rhesus monkey. J. Neurosci. 35, 112-127. doi: 10.1523/JNEUROSCI.3426-14.2015

Migliore, M., and Shepherd, G. M. (2002). Emerging rules for the distributions of active dendritic conductances. Nat. Rev. Neurosci. 3, 362-370. doi: $10.1038 / \mathrm{nrn} 810$

Miller, E. K., and Cohen, J. D. (2001). An integrative theory of prefrontal cortex function. Annu. Rev. Neurosci. 24, 167-202. doi: 10.1146/annurev.neuro.24.1.167

Mohan, H., Verhoog, M. B., Doreswamy, K. K., Eyal, G., Aardse, R., Lodder, B. N., et al. (2015). Dendritic and axonal architecture of individual pyramidal neurons across layers of adult human neocortex. Cereb. Cortex 25, 4839-4853. doi: $10.1093 /$ cercor/bhv188

Murthy, V. N., Schikorski, T., Stevens, C. F., and Zhu, Y. (2001). Inactivity produces increases in neurotransmitter release and synapse size. Neuron 32, 673-682. doi: 10.1016/S0896-6273(01)00500-1

Murthy, V. N., Sejnowski, T. J., and Stevens, C. F. (1997). Heterogeneous release properties of visualized individual hippocampal synapses. Neuron 18, 599-612. doi: 10.1016/S0896-6273(00)80301-3

Nimchinsky, E. A., Sabatini, B. L., and Svoboda, K. (2002). Structure and function of dendritic spines. Annu. Rev. Physiol. 64, 313-353. doi: 10.1146/annurev.physiol.64.081501.160008

Nusser, Z. (2012). Differential subcellular distribution of ion channels and the diversity of neuronal function. Curr. Opin. Neurobiol. 22, 366-371. doi: 10.1016/j.conb.2011.10.006

Nusser, Z., Lujan, R., Laube, G., Roberts, J. D., Molnar, E., and Somogyi, P. (1998). Cell type and pathway dependence of synaptic AMPA receptor number and variability in the hippocampus. Neuron 21, 545-559. doi: 10.1016/S0896-6273(00)80565-6

Olshausen, B. A., and Field, D. J. (2004). Sparse coding of sensory inputs. Curr. Opin. Neurobiol. 14, 481-487. doi: 10.1016/j.conb.2004.07.007

Panzeri, S., Brunel, N., Logothetis, N. K., and Kayser, C. (2010). Sensory neural codes using multiplexed temporal scales. Trends Neurosci. 33, 111-120. doi: 10.1016/j.tins.2009.12.001

Preuss, T. M. (1995). Do rats have prefrontal cortex? The Rose-Woolsey-Akert program reconsidered. J. Cogn. Neurosci. 7, 1-24. doi: 10.1162/jocn.1995.7.1.1

Rall, W. (1962). Theory of physiological properties of dendrites. Ann. N.Y. Acad. Sci. 96, 1071-1092. doi: 10.1111/j.1749-6632.1962.tb54120.x

Rall, W. (1964). "Theoretical significance of dendritic trees for neuronal inputoutput relations," in Neural Theory and Modeling, ed R. F. Reiss (Palo Alto, CA: Stanford University Press), 73-97.

Schummers, J., Mariño, J., and Sur, M. (2004). Local networks in visual cortex and their influence on neuronal responses and dynamics. J. Physiol. Paris 98, 429-441. doi: 10.1016/j.jphysparis.2005.09.017

Segev, I., and London, M. (2000). Untangling dendrites with quantitative models. Science 290, 744-750. doi: 10.1126/science.290.5492.744

Sjostrom, P. J., Rancz, E. A., Roth, A., and Hausser, M. (2008). Dendritic excitability and synaptic plasticity. Physiol. Rev. 88, 769-840. doi: 10.1152/physrev.00016.2007

Sporns, O. (2014). Contributions and challenges for network models in cognitive neuroscience. Nat. Neurosci. 17, 652-660. doi: 10.1038/nn.3690
Spruston, N. (2008). Pyramidal neurons: dendritic structure and synaptic integration. Nat. Rev. Neurosci. 9, 206-221. doi: 10.1038/nrn2286

Stuart, G., Spruston, N., Sakmann, B., and Hausser, M. (1997). Action potential initiation and backpropagation in neurons of the mammalian CNS. Trends Neurosci. 20, 125-131. doi: 10. 1016/S0166-2236(96)10075-8

Tong, G., and Jahr, C. E. (1994). Multivesicular release from excitatory synapses of cultured hippocampal neurons. Neuron 12, 51-59. doi: 10.1016/0896-6273(94)90151-1

Uylings, H. B., Groenewegen, H. J., and Kolb, B. (2003). Do rats have a prefrontal cortex? Behav. Brain Res. 146, 3-17. doi: 10.1016/j.bbr.2003.09.028

Van De Werd, H. J. J. M., Rajkowska, G., Evers, P., and Uylings, H. B. M. (2010). Cytoarchitectonic and chemoarchitectonic characterization of the prefrontal cortical areas in the mouse. Brain Struct. Funct. 214, 339-353. doi: 10.1007/s00429-010-0247-z

Vetter, P., Roth, A., and Hausser, M. (2001). Propagation of action potentials in dendrites depends on dendritic morphology. J. Neurophysiol. 85, 926-937.

Vogels, T. P., Rajan, K., and Abbott, L. F. (2005). Neural network dynamics. Ann. Rev. Neurosci. 28, 357-376. doi: 10.1146/annurev.neuro.28.061604. 135637

Waters, J., Schaefer, A., and Sakmann, B. (2005). Backpropagating action potentials in neurones: measurement, mechanisms and potential functions. Prog. Biophys. Mol. Biol. 87, 145-170. doi: 10.1016/j.pbiomolbio.2004.06.009

Wefelmeyer, W., Puhl, C. J., and Burrone, J. (2016). Homeostatic plasticity of subcellular neuronal structures: from inputs to outputs. Trends Neurosci. 39, 656-667. doi: 10.1016/j.tins.2016.08.004

Wen, Q., Stepanyants, A., Elston, G. N., Grosberg, A. Y., and Chklovskii, D. B. (2009). Maximization of the connectivity repertoire as a statistical principle governing the shapes of dendritic arbors. Proc. Natl. Acad. Sci. U.S.A. 106, 12536-12541. doi: 10.1073/pnas.0901530106

Wise, S. P. (2008). Forward frontal fields: phylogeny and fundamental function. Trends Neurosci. 31, 599-608. doi: 10.1016/j.tins.2008.08.008

Wittenberg, G. M., and Wang, S. S. (2008). "Evolution and scaling of dendrites," in Dendrites, 2nd Edn., eds G. Stuart, N. Spruston, and M. Hausser (New York, NY: Oxford University Press), 43-68.

Yuste, R. (2015). From the neuron doctrine to neural networks. Nat. Rev. Neurosci. 16, 487-497. doi: 10.1038/nrn3962

Zaitsev, A. V., Povysheva, N. V., Gonzalez-Burgosm, G., and Lewis, D. A. (2012). Electrophysiological classes of layer $2 / 3$ pyramidal cells in monkey prefrontal cortex. J. Neurophysiol. 108, 595-609. doi: 10.1152/jn.0085 9.2011

Zuo, Y., Lin, A., Chang, P., and Gan, W. B. (2005). Development of long-term dendritic spine stability in diverse regions of cerebral cortex. Neuron 46, 181-189. doi: 10.1016/j.neuron.2005.04.001

Conflict of Interest Statement: The author declares that the research was conducted in the absence of any commercial or financial relationships that could be construed as a potential conflict of interest.

The reviewer MR and handling Editor declared their shared affiliation, and the handling Editor states that the process nevertheless met the standards of a fair and objective review.

Copyright (C) 2017 Luebke. This is an open-access article distributed under the terms of the Creative Commons Attribution License (CC BY). The use, distribution or reproduction in other forums is permitted, provided the original author(s) or licensor are credited and that the original publication in this journal is cited, in accordance with accepted academic practice. No use, distribution or reproduction is permitted which does not comply with these terms. 